\title{
La crítica de Juan de santo Tomás del concepto suareciano de materia prima*
}

\author{
(The John of Saint Thomas' critique \\ of the suarecian concept \\ of the prime matter)
}

\section{LEOPOLDO JOSÉ PRIETO LÓPEZ}

Departamento de Humanidades, Universidad Francisco de Vitoria (UFV)

leopoldojose.prieto@ufv.es

ORCID: 0000-0002-0990-6445

Resumen. La figura de Juan Poinsot (Juan de santo Tomás, Joannis a sancto Thoma) se inserta en el movimiento de retorno a un tomismo libre de adherencias nominalistas promovido en el tomismo hispánico por relevantes figuras de la orden de predicadores. En tal sentido debe ser entendida la crítica de Poinsot a algunas ideas de origen escotista y ockhamista presentes en la metafísica de Suárez, referidas al estatuto ontológico de la sustancia material, tales como: la actualidad de la materia, el modo sustancial de unión, la inhesión inmediata de la cantidad en la materia y la idea de extensión entitativa (extensio entitativa).

Palabras clave: Poinsot; materia prima; cantidad; sustancia material.

Abstract. The figure of Juan Poinsot (Juan de Santo Tomás, Joannis a Sancto Thoma) is inserted in the movement of return to a Thomism free of nominalist adherences

Este artículo es una acción de ejecución del Proyecto Nacional Competitivo I+D (Convocatoria de Proyectos Excelencia 2017) “Sociedad, política y economía: Proyecciones de la Escolástica española en el pensamiento británico y anglosajón” (FFI2017-84435-P), financiado por el Ministerio de Economía y Competitividad (MINECO), del que el autor es el primer investigador principal. 
promoted in the Hispanic Thomism by relevant figures of the order of preachers. In this sense must be understood the Poinsot's critique of some ideas of Scotistic and Ockhamistic origin, present in the metaphysics of Suarez, referred to the ontological status of the material substance, such as: the actuality of matter, the substantial mode of union, the immediate inhesion of the quantity in matter and the idea of entitative extension (extensio entitativa).

Keywords: Poinsot; materia prima; quantity; material substance.

\section{Premisas}

En este epígrafe inicial exponemos aquellos aspectos del pensamiento de Juan de santo Tomás que consideramos necesarios para entender su crítica de la noción suareciana de materia prima. En tal sentido, las premisas de dicha crítica son las siguientes: a) la orientación tomista de los teólogos dominicos, especialmente italianos y españoles, de los siglos XVI y XVII; b) el tomismo esencial de Poinsot; c) el marcado contraste entre la filosofía metafísica de Suárez y la filosofía natural de Poinsot. El epígrafe concluye con la enumeración de lo que consideramos los puntos nodales de la crítica de Poinsot, que es expuesta y valorada en los epígrafes siguientes.

\subsection{El tomismo de los siglos $X V I$ y XVII entre los dominicos italianos y españoles}

Eligiendo como nombre religioso Juan de santo Tomás, Juan Poinsot (1589-1644) manifestaba al mundo el programa intelectual que había de guiar sus pasos: reproponer un tomismo puro (Rivera de Ventosa 1982, 588-589). De preclara inteligencia, Juan Poinsot pertenece a la tradición de grandes maestros de la Orden de Predicadores que pusieron en práctica la restauración del tomismo, entre quienes se contaron especialmente el Ferrariense, Cayetano, Báñez, etc. El propósito de Juan Poinsot es reivindicar, frente al tomismo marginal de otras órdenes (considerado no carente de errores), el tomismo genuino de los dominicos. Así lo expresa nuestro autor en el Tractatus de Approbatione et Auctoritate Doctrinae Angelicae Divi Thomae, actualmente publicado en el primer volumen del Cursus theologicus 
(A Sancto Thoma 1931, 221-301), donde deja constancia de su deseo de depender sólo del Aquinate. Como se ha dicho, Juan Poinsot "fue Ioannes a sancto Thoma no sólo por devoción genérica [...] sino por la fundación misma de su personalidad" (Forlivesi 2001, 6).

A lo largo del siglo XVI, a la vez que se asiste al fraccionamiento de las filosofías dependientes del platonismo y del agustinismo (en particular, escotismo y ockhamismo), se impone en el ámbito tomista, especialmente en la Orden de los dominicos, un seguimiento casi literal de los textos del Aquinate. En realidad, desde el Capítulo general de Zaragoza (1309) ya se imponía a los profesores dominicos el seguimiento disciplinar de Tomás de Aquino (y su interpretación de Aristóteles) bajo pena de pérdida de cátedra. También se establecía en él un cursus studiorum de nueve años (tres de lógica, dos de filosofía natural y cuatro de teología) basado únicamente en Tomás de Aquino. En este movimiento de repristinación tomista se inserta en la segunda mitad del siglo XVI un tomismo de comentaristas italianos de Tomás de Aquino, movido de un deseo de ortodoxia tanto eclesial como académica (cf. Gomes 1985, 47 y Gonçalves 1955, 45-51). Es el tiempo, sobre todo, de Francisco Silvestre Ferrariense (1474-1528) y Tomás de Vio Cayetano (1469-1534), este último cardenal opositor de Lutero y maestro común del tomismo renacentista. Posteriormente, la crisis de la Reforma dio un nuevo impulso a la renovación del tomismo, especialmente en España y Portugal. Así, el tomismo de comentaristas es reemplazado por un tomismo funcional, dirigido a las necesidades teológicas de la Contrarreforma y caracterizado por la exigencia de ortodoxia teológica. Es la época del Concilio de Trento (1545-1563) y de la declaración de Tomás de Aquino como Doctor de la Iglesia por obra del Papa dominico Pío V (1567). Ahora son los autores españoles los impulsores de este nuevo tomismo. Francisco de Vitoria (1486-1546) postula un tomismo contrario a los excesos del nominalismo y humanismo. A Vitoria suceden Melchor Cano (1509-1560), Domingo de Soto (1494-1569), Domingo Báñez (1528-1604), etc. A este movimiento de renovación hispánica del tomismo pertenece históricamente la figura de Juan Poinsot, decidido en la promoción de un tomismo que, como consta en el subtítulo de su Cursus philosophicus Thomisticus, quiere ser según el exacto, 
verdadero y genuino espíritu de Aristóteles y del Doctor Angélico (secundum exactam, veram et genuinam Aristotelis et Doctoris Angelici mentem).

De la obra de Juan de santo Tomás, como estudioso e intérprete de Tomás de Aquino, se ha hecho un balance general con el que no estamos del todo de acuerdo. En concreto, según Rivera de Ventosa son aspectos positivos de su obra el sentido clásico, la riqueza y precisión conceptual y el intelectualismo tomista en la plena madurez. En cambio, entiende como negativos el culto a la autoridad de Tomás de Aquino frente al estudio de los problemas, la falta de creatividad y la carencia de sentido histórico (cf. Rivera de Ventosa 1982, 583 y ss.). Sea de ello lo que fuere, lo que interesa poner de manifiesto ahora es que Juan Poinsot se consideró llamado a oponerse a aquel otro tomismo que, con un fuerte influjo escotista, estaba presente en las Disputationes metaphysicae de Suárez, en particular en la teoría suareciana del ente material.

\subsection{El tomismo esencial de Poinsot}

La filosofía natural de Juan Poinsot (o Juan de santo Tomás, 1589-1644), contenida en la segunda parte del Cursus philosophicus Thomisticus posee inequívocos elementos de modernidad, como puede verse en el tratamiento reservado a los fenómenos naturales estudiados por la naciente ciencia moderna. En su Philosophia naturalis Poinsot se interesa por los mismos fenómenos que su contemporáneo Descartes afronta en los libros III y IV de los Principia philosophiae. En concreto, en los diez Tractati de la parte II-II de su Philosophia naturalis estudia los meteoros en general (tratado $1^{\circ}$ ), la galaxia, las manchas de la Luna (tratado $2^{\circ}$ ), los meteoros ígneos (cometas, trueno y relámpago, tratado $3^{\circ}$ ), los meteoros húmedos (viento, lluvia, nieve, granizo, tratado $6^{\circ}$ ), el mar y sus movimientos (las mareas, tratado $7^{\circ}$ ), las fuentes y los ríos (tr. $8^{\circ}$ ), los terremotos y el fuego subterráneo (tr. $\left.9^{\circ}\right)$; y finalmente, los metales (tr. $10^{\circ}$ ).

Sin embargo, a los efectos de este trabajo, la figura de Poinsot interesa porque es seguramente el mayor crítico de la filosofía natural de Suárez. En tal sentido podemos afirmar que la filosofía natural de Poinsot ha sido 
elaborada con el propósito de depurar el tomismo medieval de sus adherencias nominalistas (cf. Beltrán de Heredia 1963, 670). Por ello, Poinsot se propone en buena medida matizar y valorar críticamente ciertas nociones de la filosofía natural de Suárez, como vamos a ver a lo largo de este trabajo. S. Ramírez afirmaba a este respecto que el esfuerzo intelectual de Poinsot consistió en lo esencial en el desarrollo y la defensa del tomismo, combatiendo en particular, sin la violencia de otros tiempos, a Vázquez y Suárez, de manera que como Cayetano se había opuesto a Escoto y Báñez a Molina, Poinsot se opuso al tomismo ecléctico de Suárez (cf. Ramírez 1924, 806). En concreto veremos cómo algunas de las nociones más importantes de la filosofía natural de Suárez (en particular, la materia prima con una actualidad propia en virtud de un acto entitativo suyo; la materia prima como sujeto inmediato de inhesión del accidente cantidad; la doctrina de los modos sustanciales de unión; y la idea de una extensión entitativa, no accidental, etc.), son claramente abordadas por Poinsot en diálogo crítico y en buena medida rechazadas.

\subsection{Un marcado contraste entre la filosofía metafísica de Suárez y la filosofía natural de Poinsot}

Una primera gran diferencia que salta a la vista entre Suárez y Poinsot, antes de entrar en detalles, se percibe en el diferente estatuto ontológico reservado por ambos al ente material. En concreto, mientras Suárez pone la atención en el estudio metafísico del ente o sustancia material, el enfoque de Poinsot se caracteriza por dirigirse más bien al estudio físico del ente móvil. Frente a la metafísica suareciana de la sustancia material, Poinsot propone ante todo una filosofía natural, cuyo objeto es el ens mobile. En vano se buscará una metafísica ut sic en el Cursus philosophicus Thomisticus (en adelante, Cursus). Poinsot la ha reemplazado por una filosofía natural fuertemente anclada en las obras físicas de Aristóteles. Naturalmente, dicha filosofía natural es en buena medida una metafísica. Pero ni el término metafísica ni el estilo eminentemente abstracto de otras obras de metafísica están presentes en el Cursus. 
En efecto, el primer artículo de la Philosophia naturalis del Cursus se plantea la cuestión de si el ente móvil es el objeto formal de la filosofía (Utrum ens mobile sit objectum formale philosophiae). Poinsot cree que en el análisis del objeto formal de la filosofía natural algunos autores (entre los cuales se cuentan ante todo los conimbricenses, es decir, los jesuitas de Coimbra, con Suárez a la cabeza) han reducido impropiamente la distinción entre ente material y ente móvil a una simple cuestión de palabras. En concreto:

Aunque lo móvil o mutable físicamente debe ser un cuerpo o una sustancia, sin embargo la formalidad del cuerpo explica algo distinto de la formalidad del ente móvil. En efecto, el cuerpo se dice formalmente de la raíz de la cantidad y así se define por relación con la divisibilidad. Lo móvil, en cambio, radicalmente tomado, se refiere a la raíz del movimiento, o lo que es igual, al paso de la potencia al acto [...] De manera que para distinguir la razón formal y la material en el objeto de la filosofía natural [Physica] hay que decir que la razón de la movilidad pertenece al objeto formal, mientras que la razón de cuerpo [pertenece] al objeto material (A Sancto Thoma 1678, I-II, a. 1, 342).

En suma, la filosofía natural de Poinsot es una reflexión sistemática sobre el ente móvil (en tal sentido es una física teórica). Así, a diferencia del aire netamente metafísico de la filosofía de Suárez, heredera de la tradición aviceniano-escotista (cf. Cross 1998, 13-33; Prieto López 2006, 12-13; Ward 2014, 6-40), Poinsot da mayor relieve a una perspectiva física (y con ella a la doctrina del acto y la potencia) en el estudio de la sustancia material. Con Escoto, Suárez explica que la primera división del ente (la división entre ente finito e infinito), precede a la división del ente en las diez categorías, propias únicamente del ente finito, y más en concreto, de la sustancia material. Un planteamiento de tal manera abstracto se aleja decididamente de un acercamiento físico-natural a la realidad (que imprimiría en su filosofía un sentido ascendente), privilegiando por el contrario un sentido descendente como es propio de una metafísica de la creación. De aquí toma Suárez la inspiración para eliminar de su metafísica las pruebas físicas de la existencia de Dios, a la vez que se concentra exclusivamente sobre las pruebas metafísicas, eliminando el movimiento y limitándose a la causalidad. 
De este modo, el principio aristotélico quidquid movetur ab alio movetur se transforma en Suárez en este otro: omne quod fit ex aliquo fit.

\subsection{Los puntos nodales de la crítica de Poinsot}

La necesaria concisión que este trabajo debe tener nos obliga a limitarnos a exponer la crítica de Poinsot al estatuto ontológico de la materia prima según Suárez. En concreto, vamos a estudiar la crítica de cinco ideas suarecianas: 1) la materia prima no es pura potencia, sino que posee un cierto acto; 2) la materia prima, pues, puede existir sin la forma; 3) en consecuencia, la unión de materia y forma no se da inmediatamente, sino únicamente por medio de un modo de unión; 4) el accidente cantidad inhiere directamente en la materia prima (que posee una entidad propia), no en el compuesto; y 5) es necesario distinguir entre dos formas de extensión: una entitativa y otra cuantitativa (o accidental).

\section{Definición de materia prima y carácter puramente potencial de la misma}

En la I-II ${ }^{\text {ae }}$ del Cursus la cuestión tercera, que lleva por título "Sobre los principios en particular y en primer lugar sobre la materia prima", se estudia inicialmente si la materia prima existe y qué es (art. 1: An sit et quid sit materia prima). Posteriormente se afronta la cuestión de "si la materia prima es pura potencia, porque carece de todo acto formal y entitativo" (art. 2: Utrum materia prima ex se ita sit pura potentia, quod careat omni actu formali et entitativo). Como puede verse, desde el inicio, Poinsot abre la polémica con Suárez, de quien toma los términos técnicos de acto entitativo y formal.

Según Poinsot, "por el nombre de materia prima entendemos aquella entidad que es capaz de recibir las formas sustanciales, pero que carece por sí misma de forma" (A Sancto Thoma 1678, I-II, q. 3, a. 1, 360). Prosigue, de nuevo con Aristóteles, que la materia prima puede ser definida por analogía con la materia artificial, pues así 
como de la madera o del bronce se hace una estatua, y tal madera o bronce no tiene en sí estatua alguna, sino sólo la capacidad para la estatua [...] así aquello que respecto de las cosas naturales es materia y sujeto, se entiende que no posee un ser natural, sino que únicamente tiene capacidad para el mismo, y a esto se le llama ser en potencia (A Sancto Thoma 1678, I-II, q. 3, a. 1, 360).

Tras una serie de citas de Tomás de Aquino propone Poinsot dos definiciones de materia inspiradas en Aristóteles, una positiva y otra negativa. La primera afirma:

La materia es el primer sujeto, a partir del cual algo se hace, y no según el accidente. Se dice sujeto para excluir la forma, que no es sujeto, sino lo que adviene al sujeto. Se dice primero para excluir el sujeto de las formas artificiales y accidentales, que no es sujeto primero, sino que es la misma sustancia compuesta y sustentativa de los accidentes, que es hecha a partir de aquel sujeto primero y que por ello mismo no es materia primera, sino segunda. Se dice de aquello de lo que algo se hace para excluir otras causas (A Sancto Thoma 1678, I-II, q. 3, a. 1, 361).

Posteriomente propone la conocida definición negativa, según la cual la materia de suyo no es ni qué ni cuánto ni alguna otra determinación por la que el ente sea determinado. De manera que si la materia prima es de tal naturaleza, ello significa que "carece de toda forma de determinación del ser, por lo que, como [...] explica santo Tomás, la materia no puede existir por sí sin forma, y que sólo por medio de la forma deviene un ente en acto, pues por sí misma no es más que potencia" (A Sancto Thoma 1678, I-II, q. 3, a. 1, 361).

Tras la definición, sentado el principio de que la materia prima es una entidad puramente potencial, pasa Poinsot a justificar detalladamente en el artículo segundo este carácter de potencia pura. En realidad, la potencialidad pura de la materia prima consiste en la carencia de todo acto, tanto formal como entitativo. "Llamamos acto formal a la forma que constituye con la materia algo tercero; en cambio, acto entitativo llamamos a la existencia por medio de la cual algo es formalmente constituido fuera de las causas y fuera de la nada" (A Sancto Thoma 1678, I-II, q. 3, a. 2, 362). Sin referir autor alguno, Poinsot se refiere críticamente a la teoría agustiniano-fran- 
ciscana (especialmente escotista) de la materia, según la cual la materia prima carece de determinación formal (o de acto formal), pero no de acto entitativo propio (y en consecuencia de existencia). Poinsot dice de estos autores que

no pudiendo entender cómo aquello que no es ente en acto sea algo real [...] estiman que la materia es en potencia no como si careciera de la existencia y estuviera en potencia con respecto a la misma, sino sólo como carente de forma informante, la cual se dice acto formal, y no como carente de existencia, que es el acto entitavivo (A Sancto Thoma 1678, I-II, q. 3, a. 2, 362).

Frente a esta doctrina, Poinsot propone su propia posición (que es la genuina del Aquinate) sobre el caráctrer puramente potencial de la materia prima. En efecto: "La única conclusión posible es que la materia está por sí misma en potencia tanto del acto formal como del acto entitativo, de manera que no guarda un orden inmediato a la existencia sino mediante la forma, a la cual acoge antes que a la existencia" (A Sancto Thoma 1678, I-II, q. 3, a. 2, 362: "Materia secundum se est in potentia ad actum formalem et ad actum entitativum, ita quod non habet immediatum ordinem ad existentiam, sed mediante forma, cuius est prius susceptiva quam existentiae”). Por ello, contra lo que afirman los autores más recientes (recentiores) sobre la materia prima, a saber, que "aunque está en potencia hacia todas las formas y a todo ser formal, no puede ser una nada, sino que tiene un ser entitativo" (A Sancto Thoma 1678, I-II, q. 3, a. 2, 363), Poinsot rechaza firmemente esa posición (que es la de Suárez), según la cual

la materia carece de un cierto ser natural proveniente de la forma, pero no carece de todo ser, pues tiene un acto metafísico, a saber el acto entitativo, en virtud del cual existe fuera de las causas, aunque de un modo incompleto e imperfecto, como corresponde a su género, que es imcompleto e imperfecto, y que se perfecciona por la forma (A Sancto Thoma 1678, I-II, q. 3, a. 2, 363).

Poinsot presenta una batería de razones contra la tesis de la actualidad (entitativa) de la materia prima, en apoyo del carácter puramente potencial de la misma que no es el caso de exponer aquí. Pero en lo esencial 
las reduce a dos. La primera se sitúa en el plano de los principios de la filosofía del Aquinate, que, como sabemos, Poinsot quiere reproponer. Así, en el seguimiento de santo Tomás, Poinsot afirma que "en la materia no se da un inmediato orden a la existencia, sino un orden inmediato a la forma y mediante ésta a la existencia" (A Sancto Thoma 1678, I-II, q. 3, a. 2, 362). La segunda, en cambio, se refiere a la unidad del compuesto material, que estaría comprometida si la materia prima dispusiera de un acto entitativo propio e independiente de la forma. En efecto: "en cualquier compuesto se da un único ser de existencia, por el cual existen tanto la forma como la materia y dándose el cual se hace algo único de todo el compuesto y resulta una única entidad" (A Sancto Thoma 1678, I-II, q. 3, a. 2, 362). De manera que, podemos entender, si la materia prima poseyera un acto entitativo, su relación con la forma no pasaría de ser un agregado de dos cuasi-sustancias.

\section{La materia no puede existir sin la forma... ni siquiera de potentia Dei absoluta}

Por ahora Poinsot ha sentado la dependencia esencial de la materia prima respecto de la forma para recibir la existencia. Pero, como él mismo afirma, "queda todavía por resolver la dificultad de si esta dependencia es absoluta, de manera que ni siquiera podría ser suplida por la potencia divina”. La opinión de que, de potentia Dei absoluta, tal dependencia podría ser suplida es - dice Poinsot- “comunísima entre los autores de tiempos más recientes y tiene como patrón a Scoto en 2 dist, 12, q.2 y toda su escuela" (A Sancto Thoma 1678, I-II, q. 3, a. 3, 365). Sin embargo, hay en ello hay una evidente contradicción que lleva a nuestro autor a rechazar tal posibilidad. De manera, ni siquiera apelando a la potencia divina absoluta es dable la materia prima sin la forma. Así, “decir que la materia precede a la forma es lo mismo que decir que la materia es un ente en acto sin acto, lo que implica contradicción” (A Sancto Thoma 1678, I-II, q. 3, a. 3, 366). Y lo que implica contradicción no puede ser hecho por Dios, ni siquiera de potentia absoluta. Así pues, es contradictorio afirmar que la materia es en acto o posee un acto sin la forma. De ahí que sea "lo mismo decir que la materia es algo en acto que decir que 
la materia tiene forma", y de ahí también que afirmar que "la materia es [algo] en acto sin la forma es decir simultáneamente cosas contradictorias” (A Sancto Thoma 1678, I-II, q. 3, a. 3, 366). Desde luego, es claro que Dios no puede hacer cosas contradictorias. Ésta es la opinión, según Poinsot, de Tomás de Aquino y sus discípulos más insignes, entre cuyos nombres cita a Cayetano, Ferrariense y Báñez. En sentido contrario, siguiendo a Escoto, dice de nuevo Poinsot, se expresan Suárez y los Conimbricenses, así como otros autores que, en general, son los epígonos del agustinismo filosófico y de Escoto (cf. A Sancto Thoma 1678, I-II, q. 3, a. 3, 366).

En efecto, una escuela de especial relevancia, sostenedora de la tesis de la independencia de la materia prima respecto de la forma, criticada en tal sentido por Poinsot, es la de los Conimbricenses. En efecto, en la cuestión $6^{\mathrm{a}}$ del cap. $1^{\mathrm{o}}$ del libro $1^{\mathrm{o}}$ de su Comentario a la Física de Aristóteles, titulada "Si la materia puede en virtud de la potencia divina subsistir sin forma sustancial alguna" (Utrumne materia divina virtute absque omni forma susbtantiali cohaerere possit an non), después de exponer todas las opiniones (a.1) y sus respectivos fundamentos (a. 2), los conimbricenses acogen la tesis afirmativa (a.3: Concluditur pars affirmativa quaestionis). Ya en el a. 2 se afirma: "Se establece que la materia no toma la existencia de la forma" (Statuitur materiam non capere existentiam a forma). Pero sólo en el a. 3 se asienta definitivamente la tesis. En efecto, "hay que afirmar que la materia puede en virtud de la potencia divina subsistir sin forma sustancial alguna" (Asserendumque posse materiam divina virtute sine omni forma substantiali consistere), porque siendo Dios Causa primera, puede suplir el oficio de la causa segunda en el orden de la eficiencia.

No debe ello sorprender, como quiera que Dios en la sagrada Eucaristía suple el concurso de la causa material, al conservar la cantidad y los demás accidentes (que antes inherían en la materia) fuera del sujeto ["cum etiam Deus in sacra Eucharistia concursum causae materialis sufficiat, conservando extra subiectum quantitatem, ceteraque accidentia, quae prius in materia inhaerebant"], como es opinión común de los teólogos (Commentarii Collegii Conimbricensis in Physicorum 1609, I, cap. 1, q. 6, a. 3, 215-217). 


\section{La unión de materia y forma se produce inmediatamente}

Es sabido que Suárez, acogiendo la tesis escotista de la actualidad de la materia prima, se ve obligado a considerar la materia a modo de sustancia. Ahora bien, de este modo, su unión con la forma no puede advenir más que por medio de un tertium quid, llamado por Suárez modo sustancial de unión. Sin embargo, este planteamiento suareciano, profundamente inspirado en Escoto, es explícitamente rechazado por Poinsot en su Cursus (cf. A Sancto Thoma 1678, I-II, q. 6, a. 3, 382-386). En efecto, según Poinsot, "la materia y la forma se unen inmediatemente entre sí" y "se determinan inmediatamente", de manera que "no parece que la causalidad de la forma y la materia se dé por la unión de algo distinto de ellas mismas" (A Sancto Thoma 1678, I-II, q. 6, a. 3, 383).

Poinsot conoce perfectamente la posición inspirada en Escoto relativa al modo de unión sustancial. Se refiere a ella como a una opinión bastante conocida (sententia satis celebris) según la cual "la unión es algo añadido a la forma y la materia como un cierto modo o formalidad, por medio de lo cual se da el nexo de materia y forma" (A Sancto Thoma 1678, I-II, q. 6, a. 3, 383). Ésta - dice Poinsot- es la posición de Escoto, según el cual la unión es algo a modo de relación extrínseca advenida a los propios principios de materia y forma (cf. A Sancto Thoma 1678, I-II, q. 6, a. 3, 383). Pero no sólo Escoto sostiene esta doctrina, sino que

también opinan así Suárez [...] Vázquez y muchos otros autores actuales [plures ex recentioribus], incluso tomistas [etiam thomistis], según los cuales la unión en las sustancias es un cierto modo sustancial y absoluto, por medio del cual la forma se une a la materia, aunque algunos digan que ese modo absoluto guarda una relación transcendental con el extremo unible (cf. A Sancto Thoma 1678, I-II, q. 6, a. 3, 383).

Dejamos de lado la más que interesante alusión a la relación transcendental entre materia y forma, tan común en la filosofía tardomedieval, no sin antes advertir que se trata de una noción dependiente lógicamente de la 
hipostatización de los principios de la sustancia material, es decir, materia y forma, aunque ahora no podamos abundar en ello.

Expuestas las doctrinas de Escoto y Suárez, Poinsot pasa a exponer y reivindicar la opinión del Aquinate. "En cambio, santo Tomás no reconoce modo alguno de unión que sea medio o forma constituyente unida a los extremos" (A Sancto Thoma 1678, I-II, q. 6, a. 3, 383). De todas las razones expuestas por el dominico contra la doctrina del modo sustancial de unión la más lúcida en nuestra opinión es la siguiente:

Consta que la forma por sí misma es, intrínseca y esencialmente, un acto que mira a la materia y que la materia mira a la forma. Luego [ambas entidades] por sí mismas, y no en virtud de modo alguno sobreañadido, tienen todo el fundamento y la capacidad de unirse, que es el acto y la potencia. Luego tienen la razón de unibles o de aptas para unirse por sí mismas, no por modo alguno sobreañadido (A Sancto Thoma 1678, I-II, q. 6, a. 3, 384).

En resumen, Poinsot se distancia de Escoto y Suárez y retorna al Aquinate, recordando que el principio metafísico del acto y la potencia es el único principio capaz en rigor de realizar inmediatamente (y por ello, sustancialmente) la unión de materia y forma. De manera que la unión de los extremos (materia y forma) no se obtiene por medio de algo añadido a los mismos, sino por la propia virtualidad de la que dichos extremos gozan, siendo la forma acto y la materia potencia. En breve, con palabras del propio Poinsot, "materia y forma no constituyen algo uno con unidad modal, sino con la unidad real de la sustancia"; o de otro modo, "la razón formal de la unidad de estos extremos no es un modo sobreañadido, sino la razón misma de sustancia” (A Sancto Thoma 1678, I-II, q. 6, a. 3, 384).

\section{La cantidad y la imposibilidad de una extensión entitativa}

Directamente relacionada con la materia (como sujeto primero) está la cantidad. Por eso el filósofo dominico estudia qué es, hablando con propiedad, la cantidad. En efecto, al final de la primera parte del Cursus, en la sección 
titulada Coordinatio praedicamenti substantiae (dentro de la cual se encuentra la cuestión XVI [De Quantitate]) se pregunta Poinsot en qué consiste la razón propia y formal de la cantidad (Quae sit propia et formali ratio quantitatis) (cf. A Sancto Thoma 1678, I, q. 16, a. 1, 207-212). Así, después de reproponer la definición de cantidad de Aristóteles y de reiterar contra las nominalistas (a los que se refiere expresamente) la clásica doctrina tomista de la distinción real de cantidad y sustancia material, aborda la cuestión de cuál es la esencia y cuáles los efectos de la cantidad, exactamente del mismo modo y con el mismo orden en que Suárez lo hace (cf. Suárez 1964, DM 40, 2 y 4).

Poinsot admite que es opinión común entre los autores que la esencia de la cantidad es la extensión de las partes (extensio partium), de la cual dimanan las propiedades de la medida, divisibilidad, impenetrabilidad y repleción del lugar (cf. A Sancto Thoma 1678, I, q. 16, a. 1, 207). Conoce también la noción de extensión entitativa (empleada por algunos autores recentiores, sobre todo por Suárez, a quien sin embargo no cita) y entiende por ella aquella idea relativa a la extensión de la materia previa a la inhesión de la cantidad (ante quantitatem). Afirma en tal sentido: "Fundamentum autem huius sententia [...] illa extensio entitativa partium integralium ante quantitatem". Y algo más adelante: "Sed principium impediens penetrationem contigui ab Authoribus oppositis vocatur extensio quantitativa distincta ab entitativa. Ergo ante quantitatem ponunt in substantia formalem rationem quantitatis" (A Sancto Thoma 1678, I, q. 16, a. 1, 209).

En efecto, la extensión entitativa es una de las ideas más características del estatuto ontológico de la sustancia material en Suárez (cf. Suárez 1964, DM 40, 4, especialmente n. 12). Según el granadino la materia, en virtud de su propia actualidad y entidad (que es la clave teórica profunda de toda su teoría de la sustancia material), tiene de suyo partes distintas antes de recibir la modificación accidental de la cantidad. Ello significa que dicha distinción de partes ante quantitatem "se ha de tener como una cierta extensión de la misma materia [dicenda sit extensio quaedam ipsius materiae]" (Suárez 1964, DM 40, 4, 12).

Ahora bien, según Poinsot, se trata de una noción que, además de incongruente con los principios de la filosofía del Aquinate y del Estagirita, 
es contradictoria en la medida que admite la existencia de partes en la materia con independencia de la cantidad, o lo que es igual, en la medida que "admite una sustancia sin cantidad y sin embargo con partes" (A Sancto Thoma 1678, I, q. 16, a. 1, 209). En fin, Poinsot afirma que "queda confirmado que la sustancia antes de la cantidad no tiene partes formalmente extensas, es decir, ordenadas e inconfusas [...] [o lo que es igual] no tiene partes extra partes” (A Sancto Thoma 1678, I, q. 16, a. 1, 210).

En breve, la doctrina de la extensión entitativa es una confusa idea, reliquia del nominalismo, que atribuye a la materia prima (principio constituyente de la sustancia material) el efecto de la extensión (que es propio sólo de la sustancia material ya constituida), que consiste en la diversificación de la sustancia en un orden de partes distintas. Ahora bien, según Poinsot, tal cosa sólo puede ocurrir en virtud del accidente cantidad, el cual determina extensivamente a la sustancia material, no a la materia prima. En realidad, como vamos a ver enseguida, según Poinsot, de nuevo contra Suárez, el accidente cantidad no puede inherir inmediatamente en la materia prima.

\section{Inhesión de la cantidad en el compuesto, no en la materia prima}

Nos queda por ver una última crítica de Poinsot a las ideas de Suárez sobre la sustancia material. Se trata del rechazo de la inhesión directa del accidente cantidad en la materia prima. Poinsot dedica a esta temática el artículo primero de la cuestión novena de la II-II del Cursus philosophicus, donde se aborda la cuestión de si los accidentes materiales se sustentan en todo el compuesto o sólo en la materia (Utrum accidentia materialia subjectentur in toto composito vel in sola materia).

En primer lugar distingue sujeto lógico (o de denominación) y sujeto metafísico (o de inhesión). El primero es "aquel que es denominado por la forma, es decir, el que recibe la predicación de la forma”, mientras que el segundo es "aquel sujeto que recibe la forma, es decir, el que recibe la actualidad y su ser" (A Sancto Thoma 1678, II-II, q. 9, a. 1, 666). El sujeto al que se refiere la cuestión de la inhesión de la cantidad sólo puede ser 
el sujeto metafísico. Sobre el sujeto lógico no hay dificultad entre los autores. Toda la dificultad, en cambio, está en la determinación del sujeto inmediato de inhesión (tota difficultas est de subiecto inmediato inhaesionis). En concreto, con las palabras de Poinsot, la cuestión a determinar es "en qué termina inmediatamente la inhesión del accidente y por qué [sujeto] es sustentado inmediatamente [el accidente] en el ser" (ad quid videlicet immediate terminetur inhaerentia accidentis et a quo immediate sustentetur in esse) (A Sancto Thoma 1678, II-II, q. 9, a. 1, 666).

En lo fundamental -dice Poinsot- hay dos opiniones al respecto. La primera considera que la materia prima es el sujeto suficiente de inhesión de los accidentes. La segunda, en cambio, afirma que solo el compuesto es el sujeto inmediato de los mismos (cf. A Sancto Thoma 1678, II-II, q. 9, a. 1, 666). En favor de la primera opinión cita Poinsot ante todo a Suárez (cf. Suárez 1960, DM 14, 3). De acuerdo con Suárez se muestran también -dice Poinsot- los Conimbricenses.

Citamos un largo texto de los Conimbricenses y exponemos su fundamento, que no es otro sino que estando la materia prima dotada de una subsistencia o acto entitativo propio es capaz de recibir inmediatamente la inhesión de la cantidad.

Tertia conclusio: Subjectum, cui inmmediate inhaerent materialia accidentia non est totum compositum [...] Quarta conclusio: Subjectum inhaesionis materialium accidentium est materia prima, supposito tamen actu formae substantialis. Haec conclusio est Alensis [Alejandro de Hales], Gregorii Ariminensis [Gregorio de Rímini], Hervaei [Herveus Natalis], Javelli [...], Marsilii Saxoniae [...] D. Thomas oppositum docuerit, statuens subjectum inhaesionis accidentim esse totum compositum [...] Conclusio hisce argumentis: [...] ergo accidentia materialis in sola materia inhaerent (Commentarii Collegii Conimbricensis in De Generatione et corruptione 1600, I, cap. 4, q. 4, a. 4, 56).

Posteriormente los Conimbricenses pasan a presentar la razones que avalan esta opinión, de entre las cuales extraemos esta:

Quod ex eo etiam confirmatur, quia cum quantitas, quae est fundamentum omnium materialium accidentium, sequatur materiam, ut alibi ostendimus, 
consequens est ut materia sit prima radix recipiendi accidentia materialia, et ut ipsa primo atque immediate recipiat. Praeterea materia sub actu formae nihil deest quominus possit, ac debeat recipere accidentia materialia. Igitur ipsa erit subjectum inhaesionis talium accidentium. Consecutio liquet, frustra enim quaeretur aliud subjectum, si materia ita sumpta sat[is] est. Antecedens ostenditur, quia materia prima est jam tunc subsistens, ac suopte ingenio potentia receptiva, et est ens in actu per formam substantialem. Hoc autem sufficit ad praestandum recipiendi officium (Commentarii Collegii Conimbricensis in De Generatione et corruptione 1600, I, cap. 4, q. 4, a. 4, 57).

En cambio, la segunda opinión (la de Tomás y su escuela) afirma que no es la materia, sino el compuesto sustancial el que recibe la inhesión de la cantidad. Poinsot se adhiere a la opinión del Aquinate, que expone con las siguientes palabras:

En la enseñanza de santo Tomás, como quiera que la materia es pura potencia, en modo alguno puede ser por sí sola sujeto de inhesión de los accidentes materiales, sino que el sujeto de inhesión es el mismo compuesto. La materia únicamente es receptiva de los accidentes como sujeto quo, en cuanto es aquello por medio de lo cual el compuesto recibe los accidentes después de recibida la forma sustancial en la materia. Ésta es sin duda alguna la opinión de santo Tomás, cuya enseñanza constante es que la materia prima no es sujeto de los accidentes (A Sancto Thoma 1678, II-II, q. 9, a. 1, 667).

Las razones fundamentales de la tesis del Aquinate al respecto son dos, según Poinsot. En efecto, el sujeto de inhesión debe poseer dos condiciones que no se dan en la materia prima: a saber, actualidad para sustentar y terminar en el ser (actualitate ad firmandum et terminandum in esse) y potencialidad para recibir (potentialitate ad recipiendum) (cf. A Sancto Thoma 1678, II-II, q. 9, a. 1, 667). Pues bien, en lo que concierne a la actualidad, según Poinsot, la materia prima carece de toda actualidad, tanto formal como entitativa (cf. A Sancto Thoma 1678, II-II, q. 9, a. 1, 667). Del mismo modo, en relación con la potencialidad, es patente que la materia prima no puede ser sujeto receptor inmediato de los accidentes, porque la potencialidad que le es propia mira en primer lugar a la forma sustancial y sólo en un segundo 
momento a la accidental (cf. A Sancto Thoma 1678, II-II, q. 9, a. 1, 667). En breve, solamente la materia y la forma se unen entre sí como principios constitutivos del compuesto, que es el verdadero y propio sujeto de inhesión, del que depende el accidente cantidad en su potencialidad (en virtud de la materia) y en su actualidad (en virtud de su forma).

Sin embargo, es tal el peso que Poinsot atribuye a la tesis de Suárez sobre la inhesión inmediata de la cantidad en la materia que, a pesar de haber dado ya la solución de esta cuestión, dedica aún un largo espacio a abundar en ella y confirmar su rechazo. Retorna sobre la cuestión afirmando que "conviene examinar el fundamento de [la opinión del] P. Suárez, tal como se recoge en DM 14, 3" (primo examinari oportet fundamentum P. Suárez disp. 14, sec. 3). Pues bien, dicho fundamento, como ya sabemos, no es otro que la tesis suareciana según la cual "la materia prima tiene un ser suficiente para sustentar al accidente, dado que no carece de existencia, supuesto que es un ente en acto y fuera de las causas, pues de otro modo sería nada" (A Sancto Thoma 1678, II-II, q. 9, a. 1, 669: “quod materia prima [...] habet sufficiens esse ad ipsum [accidens] sustentandum, cum non careat existentia, siquidem est ens actu et extra causas, alias esset nihil”). Y de nuevo, Poinsot responde, siguiendo al Aquinate, que la materia no posee actualidad sino por la forma, de la cual recibe la existencia; o lo que es lo mismo, la materia prima no posee un acto entitativo propio que la dote de existencia (cf. A Sancto Thoma 1678, II-II, q. 9, a. 1, 669).

\section{Recapitulación y conclusiones}

He aquí, pues, la gran cuestión debatida entre Suárez y Poinsot: la actualidad de la materia prima. Propuesta por Escoto y acogida por Suárez, Poinsot la rechaza con decisión. De ella se derivan las tesis fundamentales propuestas por Suárez relativas a la sustancia material, que Poinsot igualmente deniega en la exigencia de un tomismo puro sin concesiones a escotismo y ockhamismo. En cualquier caso, hagamos un breve repaso y valoración de las consecuencias que se derivan de esta tesis. 
En primer lugar, en lo que respecta a la materia, la distinción (de origen escotista) entre acto formal (del que la materia está privada) y acto entitativo (poseído en cambio por ésta) marca una inflexión decisiva en el estatuto ontológico de la sustancia material. En efecto, aceptada esta distinción, como Suárez hace, resulta inevitable aceptar que la materia prima posee una existencia autónoma. Ahora bien, de este modo la materia prima es pensada como una sustancia. En tal sentido Åkerlund habla acertadamente de una parcial sustancialidad de la materia prima en Suárez (cf. Åkerlund 2015, 55-57). También Heider ha hablado de la reificación suareciana de la materia prima (cf. Heider 2008, 429). Nosotros hemos llamado a este expediente la hipostatización de la materia prima (cf. Prieto López 2006, 14-15; 2017, 217). Lejos de la fórmula según la cual la materia es un principio metafísico (algo quo, como dice Poinsot), la materia prima es entendida, a la luz de un incipiente nominalismo, más bien como algo quod, es decir, como algo a modo de sustancia. Por ello, Poinsot, en su empeño de restaurar un tomismo sin concesiones nominalistas, recusa todo actualidad, también la entitativa, en la materia prima.

En segundo lugar, a la sustancialización de la materia prima acompaña inevitablemente la fragmentación de la sustancia material. Dado que dos sustancias en acto no pueden constituir una sustancia una, materia y forma quedan como dos semi-sustancias, si se nos permite la expresión, cuya unidad resulta ahora impedida. Por ello, siguiendo nuevamente a Escoto, Suárez se ve en la necesidad de apelar a la doctrina de los modos sustanciales de unión, con el propósito de procurar nuevos elementos de cohesión a la sustancia, una vez perdida su unidad. Poinsot, en cambio, tras rechazar el carácter sustancial de la materia prima, afirma que sólo en virtud de las exigencias metafísicas del acto y la potencia se alcanza la unidad de materia y forma, que, insiste el dominico, no son cosas o cuasi-cosas, sino principios filosóficos.

En tercer lugar, siempre a consecuencia de aquella hipostatización de la materia de la que venimos hablando, Suárez admite clara y reiteradamente la inhesión inmediata de la cantidad sobre la materia. La opinión de los Conimbricenses, aunque semejante a la de Suárez, es, sin embargo, más 
matizada en un sentido aristotélico (y así menos escotista). En efecto, aunque los conimbricenses admiten que el sujeto de inhesión de la cantidad es la materia prima, ésta lo es "sólo supuesto el acto de la forma sustancial" (supposito tamen actu formae substantialis). O de otro modo, admiten el carácter de sujeto de la materia prima, porque es una entidad subsistente, pero en realidad sólo en cuanto actualizada por la forma sustancial deviene capaz de ejercer el oficio de sujeto receptor (cf. Commentarii Collegii Conimbricensis in De Generatione et corruptione, I, cap. 4, q. 4, a. 4). Pero, retornando a la tesis suareciana, la idea de una materia prima que, afectada únicamente por la cantidad (como lo extenso o distendido en el espacio), puede subsistir en la realidad sin más determinación, es muy próxima a la idea cartesiana de res extensa (cf. Descartes 1996, I, 53). Es útil advertir que la res extensa cartesiana no es la sustancia material o corporal sin más. Es una abstracción matemática que aísla en la sustancia material lo puramente cuantitativo (dejando en suspenso todo otro aspecto ontológico presente en la sustancia) con el propósito de hacer una lectura meramente matemática, no física, de las sustancias naturales que proporcione al científico la certeza absoluta que sólo cabe a la geometría. Así lo afirma Descartes en los Principia philosophiae: "No admito ni se han de buscar en Física más principios que los de la Geometría o Matemática abstracta, porque sólo procediendo de este modo podemos dar demostraciones ciertas de todos los fenómenos de la naturaleza" (Descartes 1996, II, 64). Poinsot, por su parte, considerada imposible la inhesión inmediata de la cantidad en la materia prima, afirma que la cantidad sólo puede inherir en la sustancia completa (el compuesto), junto con otros accidentes, especialmente el accidente cualidad. Dicho en otros términos: el anti-aristotelismo mecanicista de René Descartes tiene un decidido rival en su contemporáneo Juan Poinsot, aunque en la historia moderna del pensamiento el influjo del teólogo hispano-portugués no ha tenido la fortuna que acompañó al filósofo francés.

Finalmente, en cuarto lugar la idea de extensión entitativa, tan peculiar de la cosmología de Suárez, es, de nuevo, otra consecuencia de la hipostatización de la materia prima. De manera que, en virtud de su actualidad y entidad propias, la materia se extiende por sí misma y tiene así una interna 
distinción de partes previa e independiente de la cantidad. Poinsot, en cambio, considera contradictoria la noción de extensión entitativa, según la cual puede darse una sustancia sin cantidad y sin embargo con partes, siendo así que tener cantidad y tener distensión de partes (extensio partium) son una y la misma cosa.

He aquí, pues, que las profundas diferencias entre la filosofía natural de Suárez y Poinsot, que, en un esfuerzo de síntesis, se reducen a la aceptación o rechazo de la actualidad de la materia prima, respectivamente, no son sino el eco, todavía vivo en el siglo XVII, de las disputas filosófico-teológicas zanjadas (aunque en falso, a la vista de su perduración cuatro siglos después) por las condenas de París y Oxford del siglo XIII del pensamiento aristotélico en favor del agustinismo filosófico.

\section{Bibliografía}

AA.VV. 1609. Commentarii Collegii Conimbricensis Societatis Jesu in octo libros Physicorum Aristotelis Stagyritæ. Coloniae: sumptibus Lazari Zetzneri.

AA.VV. 1600. Commentarii Collegii Conimbricensis Societatis Jesu in duos libros De Generatione et corruptione Aristotelis Stagyritae. Ludguni: sumptibus Ioannis Baptistae Buysson 1600.

Åkerlund, Erik. 2015. "Material Causality. Dissolving a Paradox: The Actuality of Prime Matter in Suárez”. En Suárez on Aristotelian Causality, edited by Jakob L. Fink, 43-63. Leiden: Brill.

A Sancto Thoma, Joannes. 1931. Cursus theologicus, opera et studio monachorum quorumdam solesmensium O.S.B. editus in quo quid contineatur versa pagella indicabit, vol I. Parisiis: Typis Societatis S. Joannis Evangelistae Desclée et Sociorum.

A Sancto Thoma, Joannes. 1678. Cursus philosophicus Thomisticus. Ludguni: sumptibus Laurentii Arnaud, Petri Borde, Joannis et Petri Arnaud. Para corregir algunos defectos visuales de la edición de 1678, hemos empleado también Poinsot, João. 1948-1950. Cursus philosophicus Thomisticus. 3 Bände. Nova editio a P. Beato Reiser OSB. Taurini: Marietti. Reprint 2007. Hildesheim: Georg Olms. Todos los textos empleados del Cursus, aún sin traducir al español, que se presentan aquí son de traducción propia. 
Beltrán de Heredia, Vicente. 1963. “Domingo Báñez (1528-1604)”. En “Enciclopedia de la Cultura Española”, vol. I, editada por Florentino Pérez-Embid, 669-671. Madrid: Editora Nacional.

Cross, Richard. 1998. The Physics of Duns Scotus. Oxford: Clarendon Press.

Descartes, René. 1996. Principia philosophiae. En Euvres complètes de R. Descartes, vol. VIII., editadas por Charles Adam y Paul Tannery. Paris: Vrin

Forlivesi, Marco. 2001. Le edizioni del 'Cursus theologicus' di João Poinsot (1589-1644) [http://web.tiscali.it/marcoforlivesi/mf2001e.pdf], 1-26. Accesso el 3 de enero de 2018.

Gomes, Pinharanda. 1985. Joao de santo Tomas na filosofía do Seculo XVII. Lisboa: Ministerio da Educação.

Gonçalves, António M. 1955. “Actualidade de Frei Joao de santo Tomas”. Filosofia 5: 45-51.

Heider, Daniel. 2008. “Suárez on Material Substance: Reification of Intrinsic Principles and the Unity of Material Composites”. Organon F 15/4: 423-438.

Prieto López, Leopoldo J. 2006. “Suárez, crocevia nella filosofía tra Medievo e Modernità”. Alpha Omega IX/1: 3-38.

Prieto López, Leopoldo J. 2017. “La impronta escotista en la metafísica de Suárez”. Logos: Anales del seminario de metafísica 50: 207-227

Ramírez, Santiago. 1924. “Jean de saint-Thomas”. En Dictionnaire de Théologie Catholique, vol. VIII/1, editado por Alfred Vacant, Eugene Mangenot y Emile Amann. Paris: Letouzey et Ané.

Rivera de Ventosa, Enrique. 1982. “Significación de Juan de santo Tomás en la historia del pensamiento”. Revista portuguesa de filosofía 38: 581-592.

Suárez, Francisco. 1960-1966. Disputaciones metafísicas (DM). 7 vols. Madrid: Gredos.

Suárez, Francisco. 1964. Disputaciones metafísicas. Vol. 6. Madrid: Gredos

Suárez, Francisco. 1960. Disputaciones metafísicas. Vol. 2. Madrid: Gredos

Ward, Thomas M. 2014. John Duns Scotus on Parts, Wholes and Hylepmorphism. Leiden: Brill 